\title{
SELENIUM BIOFORTIFICATION ENHANCES SOYBEAN SEMET AND COQ10 CONTENT
}

\author{
YANG, Y. L. ${ }^{1 *}-$ LIU, Y. Y. ${ }^{2}-$ JIANG, L. Z. ${ }^{3}$ \\ ${ }^{I}$ Department of Applied Chemistry, Northeast Agricultural University, Harbin 150030, China \\ ${ }^{2}$ College of Resources and Environment, Northeast Agricultural University, Harbin 150030, \\ China
}

${ }^{3}$ College of Food Science, Northeast Agricultural University, Harbin 150030, China

${ }^{*}$ Corresponding author

e-mail: yangyuling@neau.edu.cn

(Received 22 ${ }^{\text {nd }}$ Dec 2019; accepted 23 $3^{\text {rd }}$ Mar 2020)

\begin{abstract}
As a further study of the effect of selenomethionine content (SeMet) and coenzyme Q content in plants, Se-enriched soybeans were obtained by cultivating the soybeans in the presence of different concentrations of Se. The content of SeMet and coenzyme Q were determined in soybeans. The results show a positive correlation was found between the selenium concentration of Se-enriched soybeans and both the content of SeMet and the content of coenzyme $\mathrm{Q}_{10}$, which suggests that the inorganic selenium is absorbed by soybeans and converted into organic Se species with high bioavailability. The effect of SeMet on the content of coenzyme $\mathrm{Q}_{10}$ in soybeans was studied as well. The content of coenzyme $\mathrm{Q}_{10}$ increased in the Se-enriched soybeans compared to the control. There is a linear relationship between the content of coenzyme $\mathrm{Q}_{10}$ and SeMet. In conclusion, a Se-enriched treatment can raise the content of coenzyme $\mathrm{Q}_{10}$ and SeMet in soybeans, which could be used as potential functional food additives for improving soybean nutrition values subsequently human health.
\end{abstract}

Keywords: selenium, selenium fertilization, soybean, selenomethionine, coenzyme $Q_{10}$

\section{Introduction}

Selenium ( $\mathrm{Se}$ ) is an essential trace element for animals and humans (Fang et al., 2017). Low Se intake can have serious consequences on health. Animal studies have indicated that a low Se diet directly correlates with the incidence of various types of cancer (Li et al., 2008; Ding et al., 2014). Generally speaking, selenium content in most soils was low and thus plants grown on that soils contain low amount of Se (Pilon-Smits et al., 2009; Nothstein et al., 2016). Therefore, biofortification with Se had emerged as an effective strategy to increase Se content in plant-based food products. Coenzyme $\mathrm{Q}_{10}$ $\left(\mathrm{CoQ}_{10}\right.$, Fig. 1) was a lipid-soluble quinine that was widely distributed in plants and animals. CoQ 10 has many important physiological functions, including transferring electrons in the respiratory chain (Lenaz et al., 2007). CoQ 10 was a natural antioxidant and can boost the immune system (Tawfik, 2015; Ozer et al., 2017). Animal experiments had shown that Se was a component of glutathione peroxidase and can protect tissues from oxidative damage, thereby maintain the ability of cells to synthesize reduced $\mathrm{CoQ}_{10}$ and prevent the degradation of $\mathrm{CoQ}_{10}$. Selenium can promote the synthesis of $\mathrm{CoQ}_{10}$ in animals, and the content of Se was positively related to the CoQ content (Vadhanavikit et al., 1994); however, research on the relationship between Se and CoQ in plants was limited (Liu et al., 2003). Therefore, the bullet points of this study included the following two aspects: the first was biofortification of selenium in Soybean; the second was whether selenium-enriched soybeans (plants) affect $\mathrm{CoQ}_{10}$ content. 


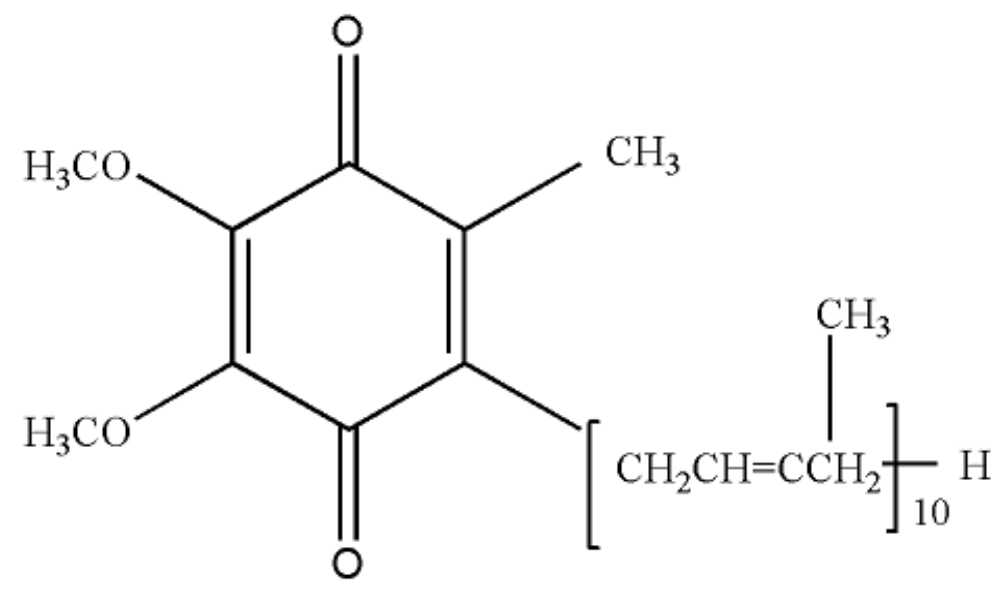

Figure 1. The structure of coenzyme $Q_{10}$

\section{Materials and Methods}

\section{Instruments and reagents}

The following instruments were used: Agilent 1200 High Performance Liquid Chromatography, DAD diode array UV detector from USA Agilent Technologies Ltd.; Z36 High-speed refrigerated centrifuge from German Hermle company; JY92- II D ultrasonic cell disrupter from Ningbo Xinzhi Bio-Technology Co., Ltd.; OSB-2100 rotary evaporator from Japan Eyela company; AFS-930 dual channel atomic fluorescence spectrometer from Beijing Titan Instruments Co., Ltd; and KXL-1010 type temperature digestion furnace from Beijing Reborn Industrial Co., Ltd.

The following reagents were used: $\mathrm{CoQ}_{10}$ standard (99.9\%): Sigma Company; Methanol, ethanol, and isopropanol chromatography from Merck Company; Nitric acid, hydrochloric acid, and perchloric acid are of pure class; Mixed acid (nitric and perchloric acid volume ratio of 4:1), potassium cyanoborohydride, sodium hydroxide, selenium standard solution $\left(1000 \mu \mathrm{g} \cdot \mathrm{ml}^{-1}\right.$ medium is $10 \%$ hydrochloric acid), Argon, and deionized water.

\section{Experimental Details and Treatments}

\section{Experimental material}

The experiment was started on May 10, 2012 in Xiangfang experimental station (east longitude $125^{\circ} 42^{\prime}$, north latitude $44^{\circ} 04^{\prime}$ ) of Northeast Agricultural University in Harbin city, Heilongjiang Province of P.R. China. Specific permissions were not required for these experiments as they were carried out at the Northeast Agricultural University. The experiments did not involve endangered or protected species.

\section{Treatments}

The soybean variety utilized in these studies was Dongnong 52 (one of the typical local varieties). The fertilizer application rates in the field experiment were as following: $\mathrm{N} 27 \mathrm{~kg} \cdot \mathrm{hm}^{-2}, \mathrm{P}_{2} \mathrm{O}_{5} 69 \mathrm{~kg} \cdot \mathrm{hm}^{-2}$, and $\mathrm{K}_{2} \mathrm{O} 50 \mathrm{~kg} \cdot \mathrm{hm}^{-2}$. The field experiment included the following 4 treatments: $\mathrm{Ck}$ as a control, no Se addition; Se1, Se2 and Se3 based on different amounts of $\mathrm{Na}_{2} \mathrm{SeO}_{3}$. Based on our previous study experience (Yang 
et al., 2014), the contents of sodium selenite were $0,10 \mathrm{~g} \cdot \mathrm{ha}^{-1}, 20 \mathrm{~g} \cdot \mathrm{ha}^{-1}, 30 \mathrm{~g} \cdot \mathrm{ha}^{-1}$ (in pure selenium meter), and the control was sprayed with distilled water only. Previous experiments have shown that higher selenium application (over $30 \mathrm{~g} \cdot \mathrm{ha}^{-1}$ ) may lead to plant visibility damage. Three replicates in the experiment were arranged randomly in the area of $300 \mathrm{~m}^{2}$ (Repetition is to avoid environmental impact on experimental results). Selenite was applied via foliar during seed filling stage. The grains were hand harvested on September 24, 2012. The experimental soil was black soil, and the water soluble selenium content of soil tillage layer was $0.014 \mathrm{mg} \cdot \mathrm{kg}^{-1}$, soil $\mathrm{pH}$ value was 7.07 , soil total $\mathrm{N} 0.105 \%$, total phosphorus $0.046 \%$, available phosphorus $25.60 \mathrm{mg} \cdot \mathrm{kg}^{-1}$, available potassium $155.65 \mathrm{mg} \cdot \mathrm{kg}^{-1}$.

\section{Methods}

\section{Determination of total selenium}

\section{Extraction of total selenium}

The sample $(0.5000 \mathrm{~g})$ was weighed in $50-\mathrm{mL}$ Erlenmeyer flasks. Ten milliliters of thick nitric acid were added for the digestion, then, $5 \mathrm{~mL}$ of mixed acid $\left(\mathrm{HNO}_{3}: \mathrm{HClO}_{4}=4: 1\right)$ were added. The digestion liquid was heated and maintained at $40^{\circ} \mathrm{C}$ until a white smoke arose. Five milliliters of $6 \mathrm{~mol} \cdot \mathrm{L}^{-1}$ thick hydrochloric acid were added until white fumes were generated. The samples were diluted to $10 \mathrm{~mL}$ with 5\% hydrochloric acid. The Se content was determined by HG-AFS. The standard solutions were prepared in the same acidic media as the samples.

\section{Determination of total selenium content}

After preheating for $30 \mathrm{~min}$, the selenium standard solution $\left(50 \mu \mathrm{g} \cdot \mathrm{mL}^{-1}\right)$ was poured into an autosampler, with a set gradient of different concentrations of standard solutions including $0.0, \quad 5.0, \quad 10.0,20.0,30.0,50.0 \mu \mathrm{g} \cdot \mathrm{mL}^{-1}$ selenium. The instrument automatically diluted the injections and drew the standard curve. The fluorescence values of each solution were determined. The selenium content in the sample was calculated using the external standard. All measurements were taken in parallel three times, the same below.

\section{Method for the determination of CoQ10}

\section{Sample pretreatment}

The soybean flour $(2.00 \mathrm{~g})$ was weighed in a $50-\mathrm{mL}$ centrifuge tube, added to $30 \mathrm{~mL}$ of $70 \%$ methanol, mixed by oscillation for $30 \mathrm{~min}$, and centrifuged for $10 \mathrm{~min}$ at $8000 \mathrm{r} \cdot \mathrm{min}^{-1}$; the supernatant was discarded. Thirty milliliters of isopropyl alcohol were added to the defatted soybean flour, and extracts were prepared by cell disruption $(400 \mathrm{w}, 2 \mathrm{~s} / 1 \mathrm{~s}, 50)$. The extracts were washed, combined and concentrated with isopropanol to a volume of $2 \mathrm{~mL}$, filtered using a $0.25 \mu \mathrm{m}$ microporous membrane, and refrigerated in the dark (He et al., 2010).

\section{Chromatographic Conditions}

A ZORBAX SB-C18 chromatographic column $(4.6 \times 250 \mathrm{~mm}, 5 \mu \mathrm{m}$, Agilent $)$ was utilized with a mobile phase that consisted of 50\% ethanol:50\% methanol at a flow rate of $2.0 \mathrm{~mL} \cdot \mathrm{min}^{-1}$. The column temperature was $30^{\circ} \mathrm{C}$, the detection wavelength was $275 \mathrm{~nm}$, and the injection volume was $10 \mu \mathrm{L}$. 


\section{Statistical Analysis}

All data were subjected to Analysis of Variance (ANOVA), and differences between the means were evaluated by Duncan's Multiple Range Test (Steel et al., 1996). SPSS statistic program (Version 18.0) was used for the data analysis. The significance of statistical analysis was to use scientific methods to get the difference between different treatments.

\section{Results}

\section{Total selenium content in Se-enriched soybean}

The determination of the total selenium contents in soybeans was shown in Fig. 2. In contrast to the control group, the total selenium contents increased significantly in the selenite-enriched soybeans. Additionally, the total Se contents in the soybeans increased as the application concentration of sodium selenite increased, which was closely related to Se of foliar application. These results indicated that the differences between the different treatments were consistent with other Se-enriched plants (Cankur et al., 2006). Eating Se-enriched soybeans might promote extra nutritional value to the human body. There was no visual plant damage during the growth of the Se-enriched soybeans.

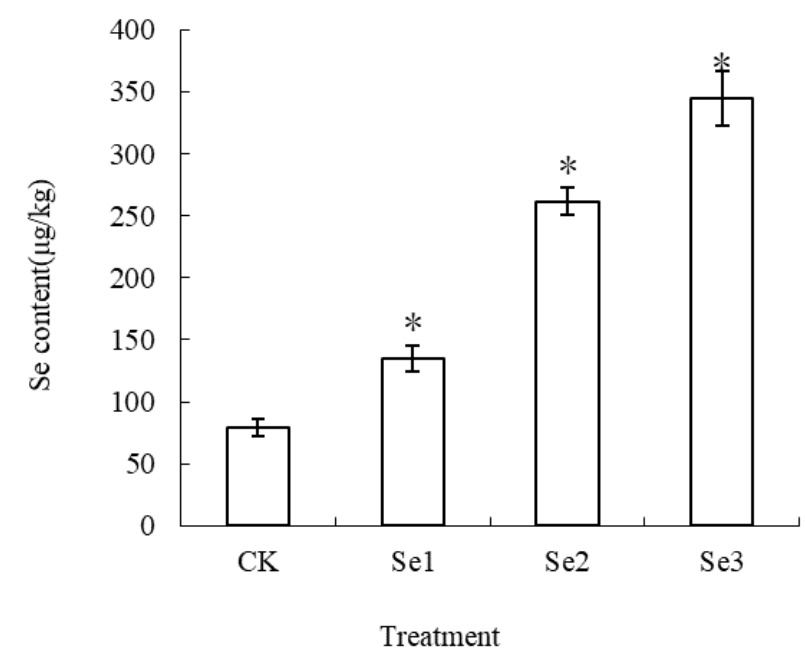

Figure 2. Se content in soybean seeds treated by different Se concentration. Data are the mean $\pm S E M . * P<0.05$ versus control (control means soybean were sprayed with equal amount of distilled water), $n=3$ (repetitions, same below)

\section{Effects of different selenium concentrations on selenomethionine content in soybeans}

Fig. 3A showed a chromatogram from the HPLC-HG-AFS analysis of the $\mathrm{Se}(\mathrm{Cys})_{2}$, Se (IV) and SeMet standard. The sample was separated on a Hamilton PRP-100 anion exchange column, with a $40 \mathrm{mmol} \cdot \mathrm{L}^{-1}\left(\mathrm{NH}_{4}\right)_{2} \mathrm{HPO}_{4}$ solution as the mobile phase (pH 6.0) and a flow rate of $0.5 \mathrm{~mL} \cdot \mathrm{min}^{-1}$.

Determination of SeMet in the soybean extracts was carried out according to the above optimized conditions. An overlay chromatogram of SeMet in the soybean extract and standard curve was shown in Fig. 3B. Using retention time matching, SeMet content in the soybean extract can be determined. 

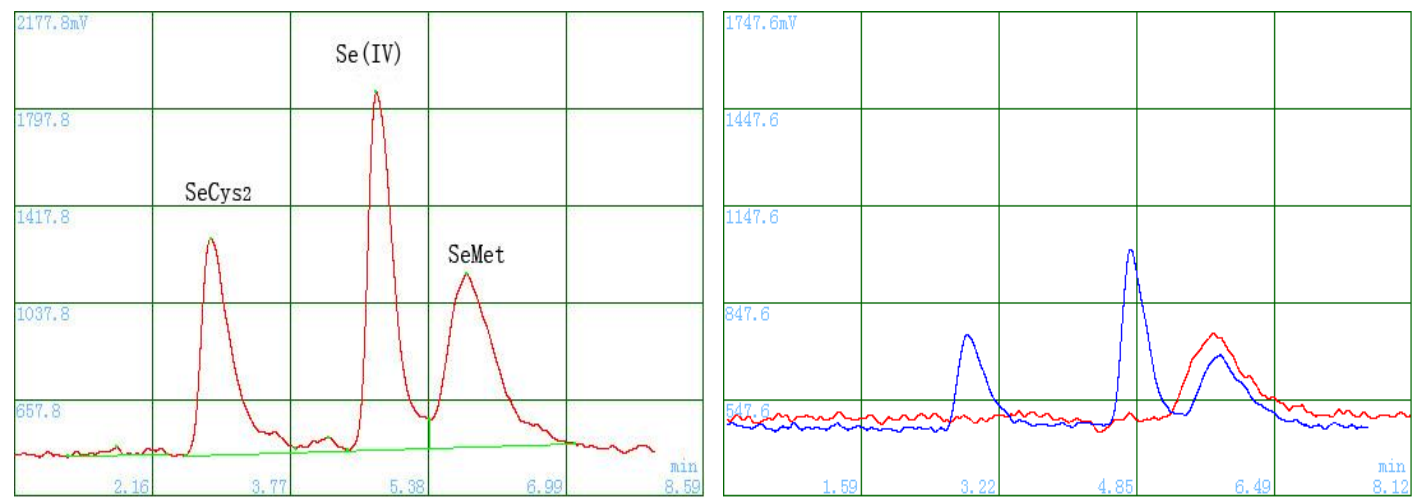

Figure 3. Chromatogram of $\mathrm{Se}(\mathrm{Cys})_{2}, \mathrm{Se}(\mathrm{IV})$ and SeMet: A Standard chromatogram of $\mathrm{Se}(\mathrm{Cys})_{2}, \mathrm{Se}(\mathrm{IV})$ and SeMet; B Overlay chromatogram of SeMet in the soybean extract and standard curve

The content of SeMet in the selenite-enriched soybeans was indicated in Fig. 4. Compared with the control, the content of SeMet in the selenized soybeans was increased, and increased as the application concentration of sodium selenite increased. There were significant differences between the treatments. The SeMet contents of Se1, Se2 and Se3 treatment were 5.85 times, 11.06 times and 18.06 times higher than that of CK.

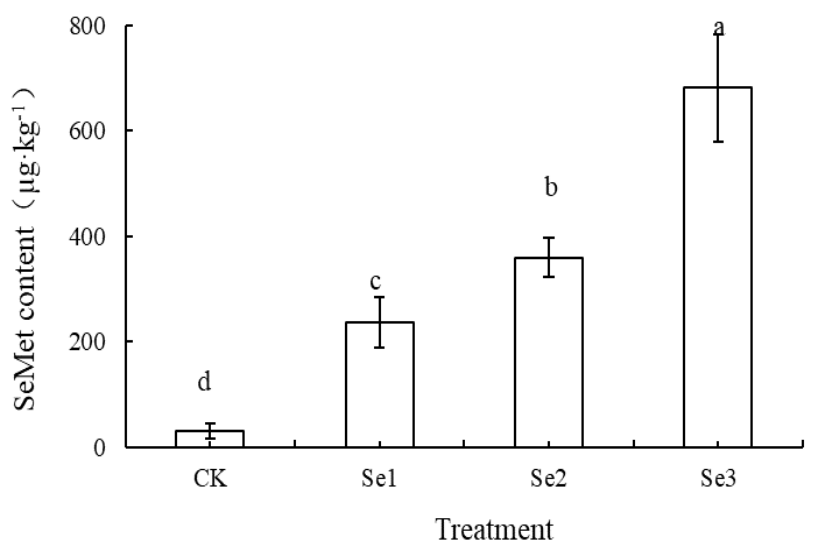

Figure 4. Effects of the Se rates on the selenomethionine content in soybean seeds. Data are the mean \pm SEM. $a, b, c, d, P<0.05$ versus control (control means soybean were sprayed with equal amount of distilled water), $n=3$

\section{Effects of different selenium concentrations on CoQ10 content in soybeans}

$\mathrm{CoQ}_{10}$ analysis using HPLC-UV. Fig. 5A showed a chromatogram from the HPLC-UV analysis of the CoQ 10 standard. Fig. $5 B$ shows an overlay chromatogram of $\mathrm{CoQ}_{10}$ in the soybean extract. The method resulted in excellent resolution of $\mathrm{CoQ}_{10}$ from the other lipophilic components of the 2-propanol extract with the $\mathrm{CoQ}_{10}$ observed at a retention time of $12.5 \mathrm{~min}$. By retention time matching, we can see that the absorption peak marked 1 was the $\mathrm{CoQ}_{10}$ standard and the absorption peak marked 2 was the $\mathrm{CoQ}_{10}$ in the soybean extract. 

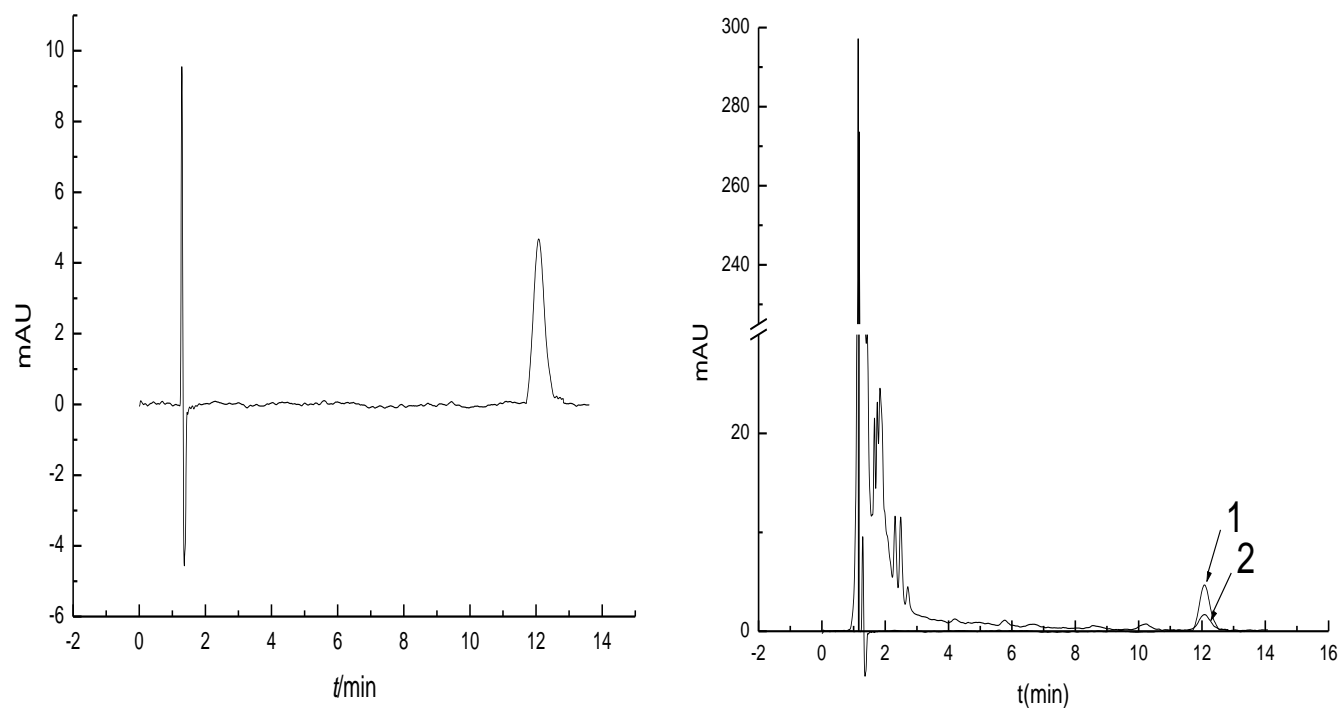

Figure 5. Chromatogram of the $\operatorname{Co}_{10}$ : A Chromatogram of the CoQ $Q_{10}$ standard; $B$ Overlay chromatogram of $C o Q_{10}$ in the soybean extract (1. Co $Q_{10}$ standard; 2. Co $Q_{10}$ in soybean extract)

The contents of $\mathrm{CoQ}_{10}$ in the soybean samples were indicated in Fig. 6. Compared with the control, the content of $\mathrm{CoQ}_{10}$ in the selenized soybeans was increased, which resulted an increased application concentration of sodium selenite. The CoQ 10 levels in $\mathrm{Se} 1, \mathrm{Se} 2$ and $\mathrm{Se} 3$ increased by 0.51-2.27 times compared to those of the control.

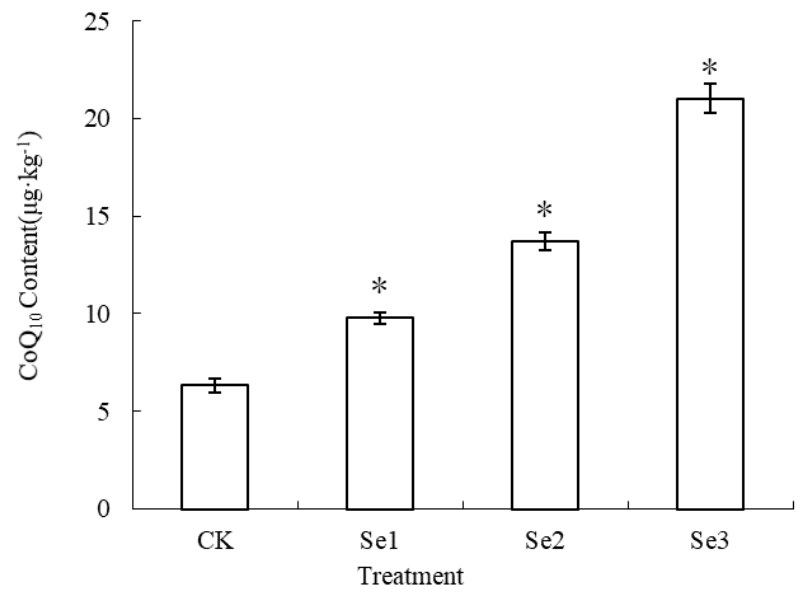

Figure 6. Content of $\mathrm{Co}_{10}$ in soybean seeds. Data are the mean $\pm S E M . * P<0.05$ versus control (control means soybean were sprayed with equal amount of distilled water), $n=3$

As seen in Fig. 7, the soybean seeds showed a good linear relationship between the content of $\mathrm{CoQ}_{10}$ and the SeMet content under different contents of selenium fertilizer in the test, using the linear equation: $\mathrm{y}=0.0256 \mathrm{x}+5.4321$. This result was likely because selenium can promote the synthesis of $\mathrm{CoQ}_{10}$, which increased the $\mathrm{CoQ}_{10}$ content in the soybean seeds. 


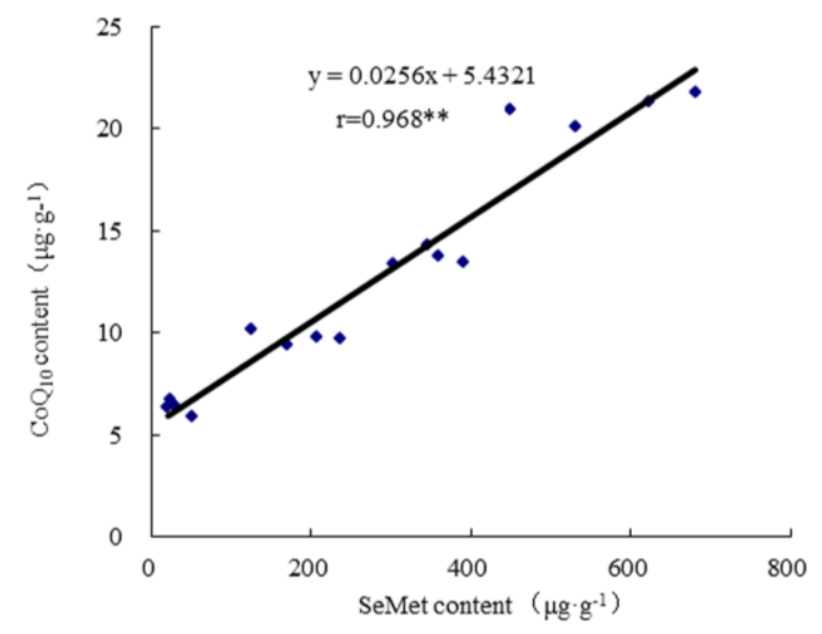

Figure 7. The relationship between the content of CoQ $Q_{10}$ and SeMet in soybeans. Data are the mean $\pm S E M . * * P<0.01$ versus control (control means soybean were sprayed with equal amount of distilled water), $n=3$

\section{Repeatability and recovery test}

Four soybean flour, one blank, the remaining three were added $200,300,400 \mu \mathrm{L}$ of the standard $100 \mu \mathrm{g} / \mathrm{mL}$, the reproducibility and recovery rate of the solution were tested. Repeat two times to take the average as a result. The CoQ ${ }_{10}$ content of blank samples was deducted and the recovery rate was calculated. The results showed that the recovery rate was $81.29 \%-87.64 \%$. The recovery and reproducibility were good.

\section{Discussion}

Plants have the capability to convert inorganic Se into organic Se such as Se-Cys and thus plant metabolism can be beneficially exploited for obtaining Se-rich crop, commonly known as biofortification (Pilon-Smits et al., 2009; D'Amato et al., 2018). Se was considered as a useful element, but not an essential element for higher plants. Se improves photosynthetic rate, growth and biomass accumulation in a range of plant species (Pilon-Smits et al., 2009). Previous research has shown that SeMet was the primary selenium compound in the bean (Chan et al., 2010). According to the reports of Gao et al. (1999), methionine (Met) can significantly improve CoQ 10 content in tobacco. Li et al. (2009) found that certain concentration of Met had a good effect on the growth of tobacco cells and the synthesis of $\mathrm{CoQ}_{10}$ in tobacco experiments. Met was a methyl donor that can enrich the sources of raw materials for the synthesis of $\mathrm{CoQ}_{10}$ and increase the $\mathrm{CoQ}_{10}$ content. Possible mechanism for catalytic body by adenosyltransferase, Met reacted with ATP to form the active S-adenosylmethionine (SAM). The active methyl can be transferred to various methyl acceptors to form methyl compounds. Under different methyl transferase enzymes, three methyls of $\mathrm{CoQ}_{10}$ were provided by S-adenosine methionine (Fofana et al., 2014) and selenium can promote the synthesis of Met. Therefore, an increase in the amount of selenium can improve the content of the methyl donor precursor of Met for the synthesis of $\mathrm{CoQ}_{10}$, thereby increased the $\mathrm{CoQ}_{10}$ levels (Yu, 2001; Fofana et al., 2014). 
Early studies have found that selenium has affected on the content of $\mathrm{CoQ}_{10}$ in animals. Therefore, we were interested in the content of $\mathrm{CoQ}_{10}$ in Soybean after selenium fertilization. Vadhanavikit et al. (1994) studied the effect of long-term (18 months) selenium deficiency on the levels of liver coenzyme $\mathrm{Q}$ in the rat. The results showed that level of coenzyme $\mathrm{Q}_{10}$ in the liver of selenium-deficient rats were $67 \%$ of the levels in selenium-adequate animals. According to Pedersen et al. (1999) survey, $\mathrm{CoQ}_{10}$ in the Eskimos living in Greenland was significantly higher than that in other regions population, and it was significantly positively related to the intake of selenium in the diet. This was attributed to the marine animal diet, and the selenium content of marine animal was generally high. Animal experiments had also confirmed that adding selenium to animal feed can increase the level of $\mathrm{CoQ}_{10}$ in the heart. The results of this experiment are of great significance to the study of the effect of selenium on coenzyme $\mathrm{Q}_{10}$ content in plants.

\section{Conclusion}

The effect of the content of SeMet on $\mathrm{CoQ}_{10}$ in soybeans was reported for the first time. In this study, the content of SeMet and CoQ 10 was determined in soybeans. The application of increased selenium concentrations can significantly improve the $\mathrm{CoQ}_{10}$ in soybean seeds.

Acknowledgements. The study was funded by the Heilongjiang postdoctoral fund (China, Grant no.LBH-Z16016).

\section{REFERENCES}

[1] Cankur, O., Yathavakilla, S. K. V., Caruso, J. A. (2006): Selenium speciation in dill (Anethum graveolens L.) by ion pairing reversed phase and cation exchange HPLC with ICP-MS detection. - Talanta 70: 784-790.

[2] Chan, Q., Afton, S. E., Caruso, J. A. (2010): Selenium speciation profiles in seleniteenriched soybean (Glycine Max) by HPLC-ICPMS and ESI-ITMS. - Metallomics 2: 14753.

[3] D'Amato, R., Fontanella, M. C., Falcinelli, B., Beone, G. M., Bravi, E., Marconi, O. (2018): Selenium biofortification in Rice (Oryza sativa L.) sprouting: effects on se yield and nutritional traits with focus on phenolic acid profile. - Journal of Agricultural and Food Chemistry 66: 4082-4090.

[4] Ding, G. B., Nie, R. H., Lv, L. H., Wei, G. Q., Zhao, L. Q. (2014): Preparation and biological evaluation of a novel selenium-containing exopolysaccharide from Rhizobium sp.N613. - Carbohydrate Research 109: 28-34.

[5] Fang, Y., Chen, X., Luo, P. Z., Pei, F., Kimatu, B. M., Liu, K. L., Du, M. J., Qiu, W. F., Hu, Q. H. (2017): The Correlation Between In Vitro Antioxidant Activity and Immunomodulatory Activity of Enzymatic Hydrolysates from Selenium-Enriched Rice Protein. - Journal of Food Science 82: 517-522.

[6] Fofana, B., Main, D., Ghose, K. (2014): Selenomethionine and Total Methionine Ratio is Conserved in Seed Proteins of Selenium-Treated and Nontreated Soybean, Flax, and Potato. - Crop Science 54: 2551-2561.

[7] Gao, X. Y., Kang, Q. L., Mu, H. (1999): Effects of a few Organic Substances on the Formation of Coenzyme Q10 in Tobacco (Nicotiana tobacum L.) Cells in Suspension Culture. - Chinese Journal of South China Agricultural University 20: 51-56. 
[8] He, Q., Lu, L. B., Zheng, X. H. (2010): Qualitative and quantitative analysis of coenzyme Q10 from Soybean. - J. Chin. Cereals and Oils Association 25: 126-128.

[9] Lenaz, G., Fato, R., Formiggini, G., Genova, M. L. (2007): The role of Coenzyme Q in mitochondrial electron transport. - Mitochondrion 7S: S8-S33.

[10] Li, G. X., Lee, H. J., Wang, Z. (2008): Superior in vivo inhibitory efficacy of methylseleninic acid against human prostate cancer over selenomethionine or selenite. Carcinogenesis 29: 1005-1012.

[11] Li, Y. H., Lv, C. M., Fan, H. Y. (2009): The effect of precursor substances on the synthesis of coenzyme Q (10) in tobacco cells. - Tobacco Science and Technology 263: 51-55.

[12] Liu, Y., Yu, Y., Lou, S. G., Peng, X., Jiang, B. (2003): Effects of selenium on CoQ10 content and ultrastructure of mitochondria and chloroplast in Soybean Leaves under continuous cropping stress. - The Tenth National Congress and the fifth Cross Strait Academic Symposium on Soil and fertilizer China Soil Society: 136-138.

[13] Nothstein, A. K., Eiche, E., Riemann, M., Nick, P., Winkel, L. H. E., Göttlicher, J., Steininger, R., Brendel, R., von Brasch, M., Konrad, G., Neumann, T. (2016): Tracking Se assimilation and speciation through the rice plant - nutrient competition, toxicity and distribution. - Plos One 11: e0152081.

[14] Ozer, E. K., Goktas, M. T., Kilinc, I., Pehlivan, S., Bariskaner, H., Ugurluoglu, C., Iskit, A. B. (2017): Coenzyme Q10 improves the survival, mesenteric perfusion, organs and vessel functions in septic rats. - Biomedicine \& Pharmacotherapy 91: 912-919.

[15] Pedersen, H. S., Mortensen, S. A., Rohde, M. (1999): High serum coenzyme Q10, positively correlated with age, selenium and cholesterol, in Inuit of Greenland. Biofactor 9: 319-323.

[16] Pilon-Smits, E. A., Quinn, C. F., Tapken, W., Malagoli, M., Schiavon, M. (2009): Physiological functions of beneficial elements. - Current Opinion in Plant Biology 12: 267-274.

[17] Steel, R. G., Dickey, D. A., Torrie, J. H. (1996): Principles and procedures of statistics: A biometrical approach. - McGraw-Hill College 672.

[18] Tawfik, M. K. (2015): Combination of coenzyme Q10 with methotrexate suppresses Freund's complete adjuvant-induced synovial inflammation with reduced hepatotoxicity in rats: effect on oxidative stress and inflammation. - International Immunopharmacology 24: 80-87.

[19] Vadhanavikit, S., Ganther, H. E. (1994): Selenium Deficiency and Decreased Coenzyme Q Levels. - Molecular Aspects of Medicine 15: s103-s107.

[20] Yang, Y. L., Liu, Y. Y. (2014): Distribution of selenium in selenite-enriched soybean. Journal of Chemical and Pharmaceutical Research 6(4): 318-321.

[21] Yu, Y. (2001): Effeets of Selenium on CoQ10 and Membrane Lipid Peroxidation of soybean under Salt and Continuous Cropping Stress. - Northeast Agriculture University, Harbin. 